\title{
Study on IOT based Architecture of Logistics Service Supply Chain
}

\author{
Wei Liu and Zhijun Gao \\ College of Transport and Communications, Shanghai Maritime University, \\ Shanghai, CHINA \\ weiliu@shmtu.edu.cn
}

\begin{abstract}
In order to study the effect of the internet of things (IOT) on the architecture of logistics service supply chain (LSSC), this paper summarizes the application of IOT in related fields on the basis of the theories of IOT, analyzes the effect of IOT on logistics/service flow, information flow and fund flow in LSSC and the effect on the structure of LSSC, builds the architecture of LSSC based on IOT, and finally forecasts the application prospect of IOT in LSSC.
\end{abstract}

Keywords: internet of things; IOT effect; logistics service supply chain; architecture

\section{Introduction}

In the era of service economy, the continuous increase and rapid development of product servitization and service outsourcing lays a solid foundation for the formation and development of logistics service supply chain (LSSC) [1]. As a typical service supply chain, LSSC has been paid continual attention by scholars. At presents, the studies on LSSC by scholars are mainly concentrating on the connotation $[2,3]$, conceptual modal [2-4], risk management[5,6], profit distribution[7], order allocation[8,9,10], coordination mechanism [11, 12], quality coordination[13], cooperation and coordination[14] and management control system[15]. However, the emergency of the internet of things(IOT) has greatly influenced logistic service industry and has entirely changed the operation mode and architecture of logistic system. This paper takes LSSC as the object of the research, analyzes the effect of IOT on logistics/service flow, information flow and fund flow in LSSC and the effect on the structure of LSSC, and on this basis, builds the architecture of LSSC based on IOT.

\section{IOT and its Application}

The Internet of Things is a novel paradigm that is rapidly gaining ground in the scenario of modern wireless telecommunications [16]. The basic idea of the concept is the pervasive presence around us of a variety of things or objects - such as RFID tags, sensors, actuators, mobile phones, etc., - which, through unique addressing schemes, are able to interact with each other and cooperate with their neighbors to reach common goals [17]. With the development of IOT techno- ledges, the new paradigm will play a leading role in the near future.

\section{A. Research on the concept and features of IOT}

In the respect of technology, IOT is the outcome of deepened and extended Internet application. It's an Internet application which involves three kinds of technology, that is, perception, transmission and intelligent processing. In the respect of development, the basic theories and key technology of IOT are still at primary stage. Xu et al., (2012) 
divided the evolution of IOT into three stages: stages of RFID-based "internet of things" and (wireless) sensor and actuator network and smart objects/cooperating objects [18], the internet of things combines sensor technology, communication network, internet technology and intelligent computing technology and so on, to achieve sensor and reliable convey and intelligent processing[19]. According to the research of Wang Rui Gang (2012), the main features of IOT are self-feedback architecture, 3C (the integration of communication technique, computer technique and control technique), security, complex networks and complex ecosystem [20]. D. Miorandi et al., (2012) summarized the following key system-level features that IOT needs to support: devices heterogeneity, scalability, ubiquitous data exchange through proximity wireless technologies, energy-optimized solutions, localization and tracking capability, semantic interoperability and data management, embedded security and privacy-preserving mechanisms[21]. It classified main concept, technology and standard of LSSC from different perspectives. IOT paradigm in three perspectives is shown in Figure 1 [16].

\section{B. Research on the Application of IOT}

IOT has very wide application which is involved with every aspect of production and life. D. Miorandi et al., (2012) [21] pointed out the application in security, privacy and trust based on the research on the key technologies of IOT. L. Atzori et al., (2010) [16] pointed out that IOT application can be divided into several fields: (1) Transportation and logistics domain; (2)Healthcare domain; (3)Smart environment (home, office, plant) domain; (4)Personal and social domain. Lu Lin (2012) [22] integrated internet, IOT and information network of agriculture product based on supply chain management method, built new management modal of agriculture product supply chain and put forward agriculture product supply chain management system based on IOT. Xu et al., (2012) [18] built and described fault prediction system based on IOT. Wang Huailin (1009) [23] analyzed the combination of the IOT and the supply chain and the decision-making modals of adopting the IOT by enterprises, and put forward recommendations from government and enterprises perspectives.

In summary, the study on IOT still concentrates on concept, key technology and features and the study on IOT application is still at discussion stage. This paper took LSSC as the object of the research and analyzed the effect of IOT on logistics/service flow, information flow and fund flow in LSSC and the effect on the structure of LSSC. On this basis, it built the architecture of LSSC based on IOT to provide theoretical basis for applying IOT in LSSC.

\section{The Effect of IOT on the Links in LSSC}

As an important industry in the services industries, the logistics industry plays an important role in economic development. Enhanced integration with the industry, the fierce market competition and specialization refinement promote the emergence of different logistics organization in the modern logistics industry. With integrity and complexity increase of the logistics service outsourcing, the logistics organizations set customers' logistics needs as a starting point, form a complete supply and demand process of the logistic services after a service process of mutual relationship between supply and demand. These multi-level supply and demand relations constitute the logistics service supply chain (LSSC). As a sub-supply chain of the product, supply chain provides integrated logistic services. 


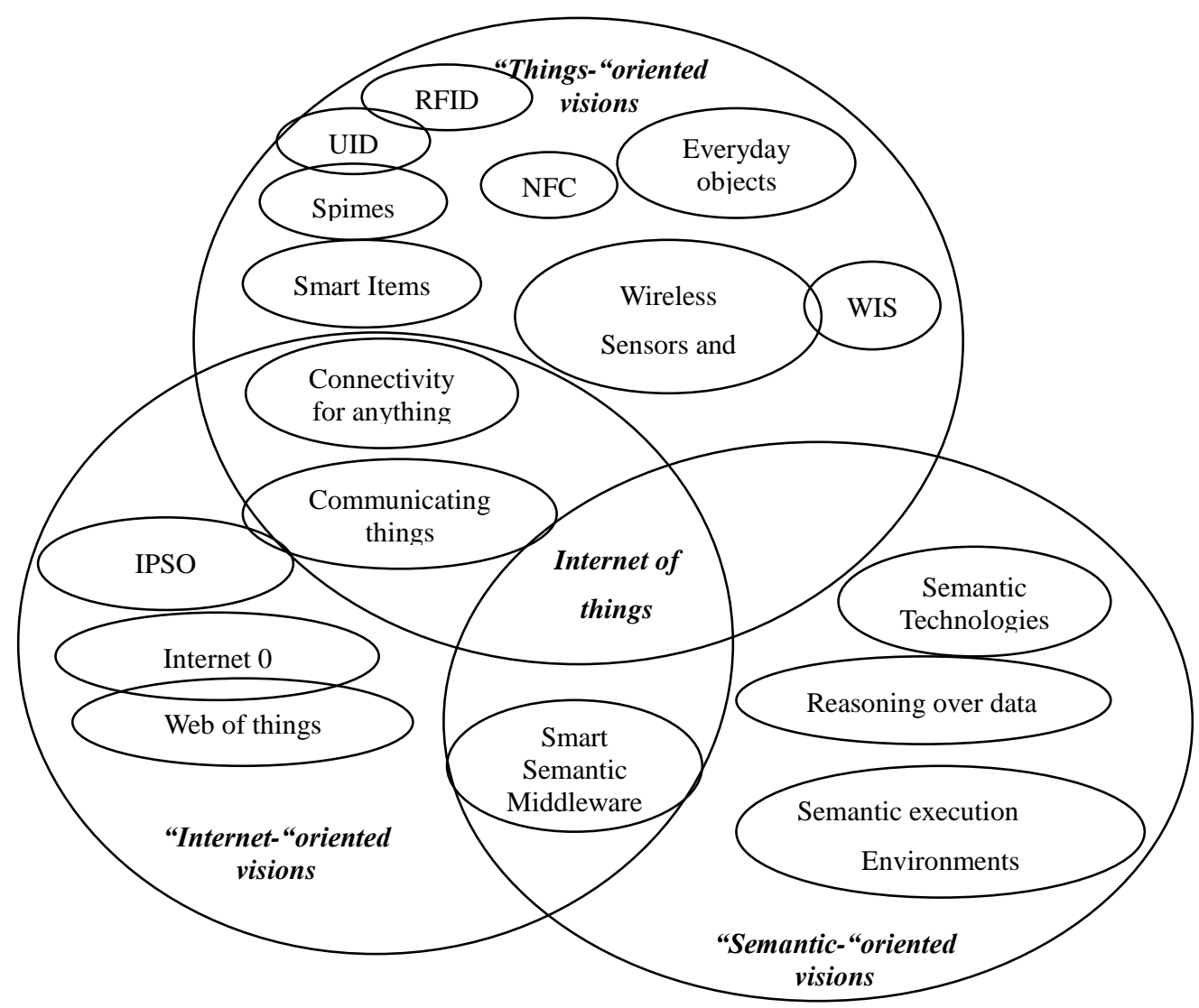

Figure 1. "Internet of Things" Paradigm as a Result of the Convergence of Different Visions

In order to improve the links in LSSC, to improve logistics/service flow, information flow and fund flow in LSSC, to improve the operation efficiency of LSSC, core enterprises build LSSC management information platform based on IOT and connect this system to the net of node enterprises in LSSC.

(1) Designing logistic supplies chain solution. Designing logistic and supply chain solution is the beginning of entire logistic service process and its quality influences the quality of logistic service and the performance and reputation of IOT. It mainly shows in these aspects: the first, making it more convenient to communicate among subcontractor, integrated provider and customers; the second, making it faster to innovate and determine; the third, improving the satisfaction to solutions greatly.

(2) Purchasing logistics capability. The analysis of logistics demand is the beginning of logistics capability purchasing. After IOT is applied, LSSC is able to do intelligent analysis, make plans of logistics capability demand depend on logistics demand, insure the betimes of logistics capability supply and save manpower.

(3) Logistics service progress. Logistics service progress is the key to entire logistics service supply and demand. Its quality directly relates to the satisfaction of customer and the reputation of LSSC. LSSC information platform is able to monitor the operation of transport link, storage link and other links momentarily and insure the betimes, safety, reliability and satisfaction after IOT is applied. 


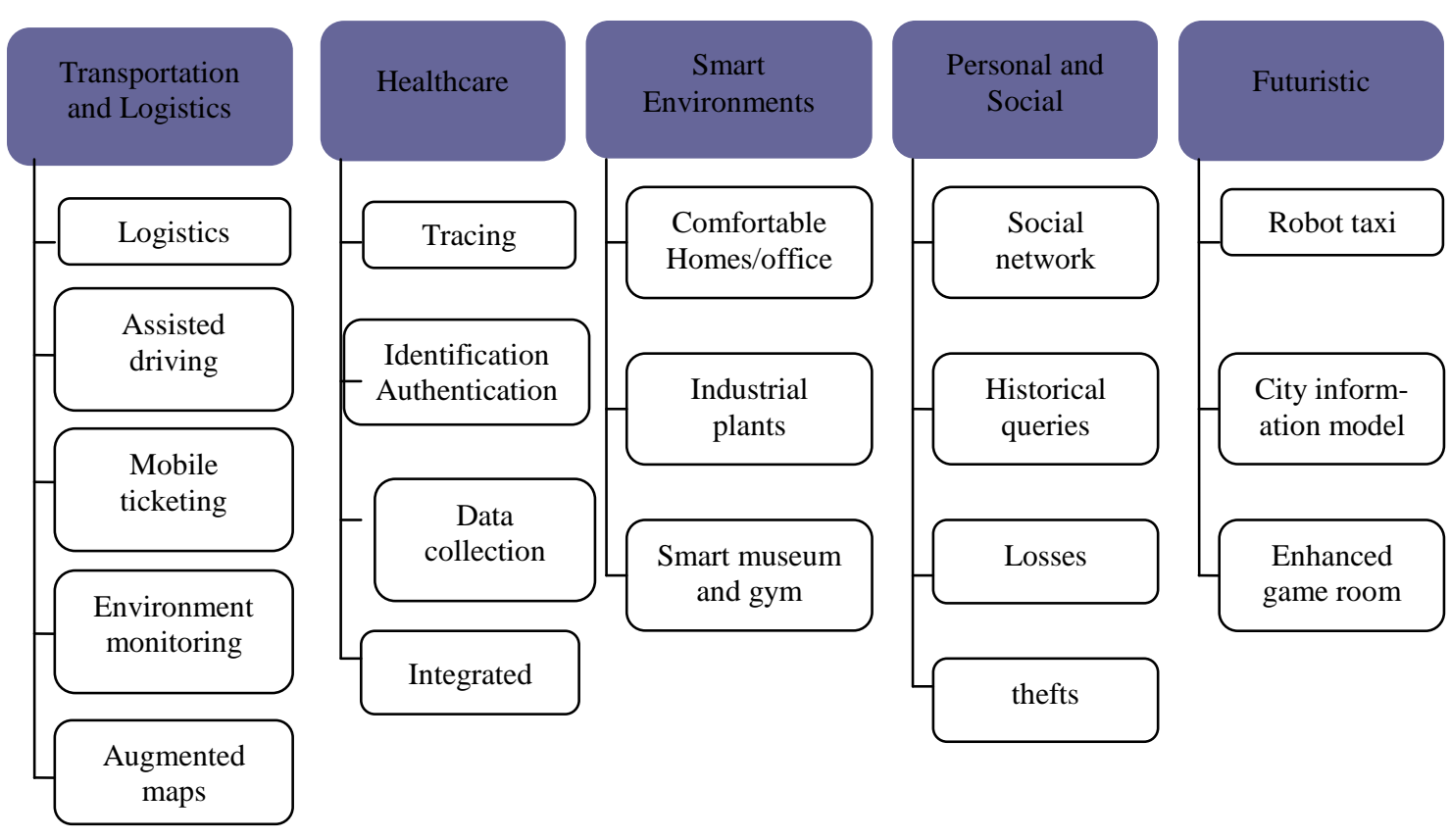

Figure 2. Applications Domains and Relevant Major Scenarios

(4) Logistics service feedback. Logistics service feedback is the key link that improved logistics service. Node enterprises got the comments which logistics demander made on service, communicate with customers and improve the logistics service progress and solution from IOT platform so that logistics service was improved.

\section{The Effect of IOT on the Material Flow in LSSC}

Modern logistics contains all links in supply chain, not only means transportation and storage. Modern logistics integrated purchasing, storage, transportation, manufacturing, wholesale, retail and after service. It provides integrated service for supply chain that embedding LSSC into manufacturing supply chain. IOT makes the service provided by LSSC more intelligent, fast and convenient, visualize and flexible, achieving "large logistics".

Achieving the intellectualization of LSSC. The application of intelligent devices and technology, such as computer technology, intelligent chip as well as sensor technology, and the application of intelligent algorithm like cloud computing and granular computing promote the intellectualization of LSSC. The work which is operated traditionally by human has been operated by intelligent services gradually, such as intelligent warehouse.

Achieving the high speed and convenience of LSSC. IOT integrates subcontractor, integrated provider and customers in LSSC, solves the disjunction problem of them and achieves seamless connection among participants. Every effective action of participant can be realized by other participants so that they can take actions to cooperate and support, making logistics service integrated and rapid.

Achieving the visualization of LSSC. The broad coverage sensor network makes the entire process of LSSC visible. Visual logistics improve the service quality through monitoring the logistical process and effective emergency treatment.

Achieving the flexibility of LSSC. In the IOT circumstances, it meets customers' demands of "multi-variety, small-batch, multi-batch and short-period" and organizes and practice logistics service flexibly that all links in LSSC can be completed involved intelligent system. 


\section{The Effect of IOT on the Information Flow in LSSC}

Information is the key which determines whether the operation of LSSC is success, because information is node enterprises' decision basis. Information symmetry directly influences the entire operation performance of LSSC. Information flow is the media of LSSC, the basis of logistic supply chain solution logistics capability purchasing and logistics service progress. Information flow integrated all links and participants in LSSC. The application of IOT met the demands of participants for information.

(1) Achieving the high speed for the transmission of information flow. In comparison to traditional LSSC, LSSC embedded with IOT makes the information transmission faster and achieves automation and diversification of information collection. It's easy to share information with IOT and overcome the bullwhip effective of LSSC.

(2) Achieving the intelligence for processing information flow. It helps to intelligent processing of logistics information, such as, information perception, information measurement, information identification, information acquisition and the input, output, processing and transformation of information, that IOT applied intelligent devices and new technology like grid computing cloud computing and SaaS (Software-as-a-service).

(3) Achieving the networking for the dissemination of information flow. In LSSC, the traditional information dissemination was linear, however, after IOT is applied, information dissemination has been networked (as shown in fig 3) because different participants exchanges information. The flat mode of transmission levels, the high degree of sharing information and the great decrease of information distortion, overcame the bullwhip effective, makes every member of LSSC be able to get accurate logistics capability requirement information, decreases recourse waste and improves customer satisfaction.

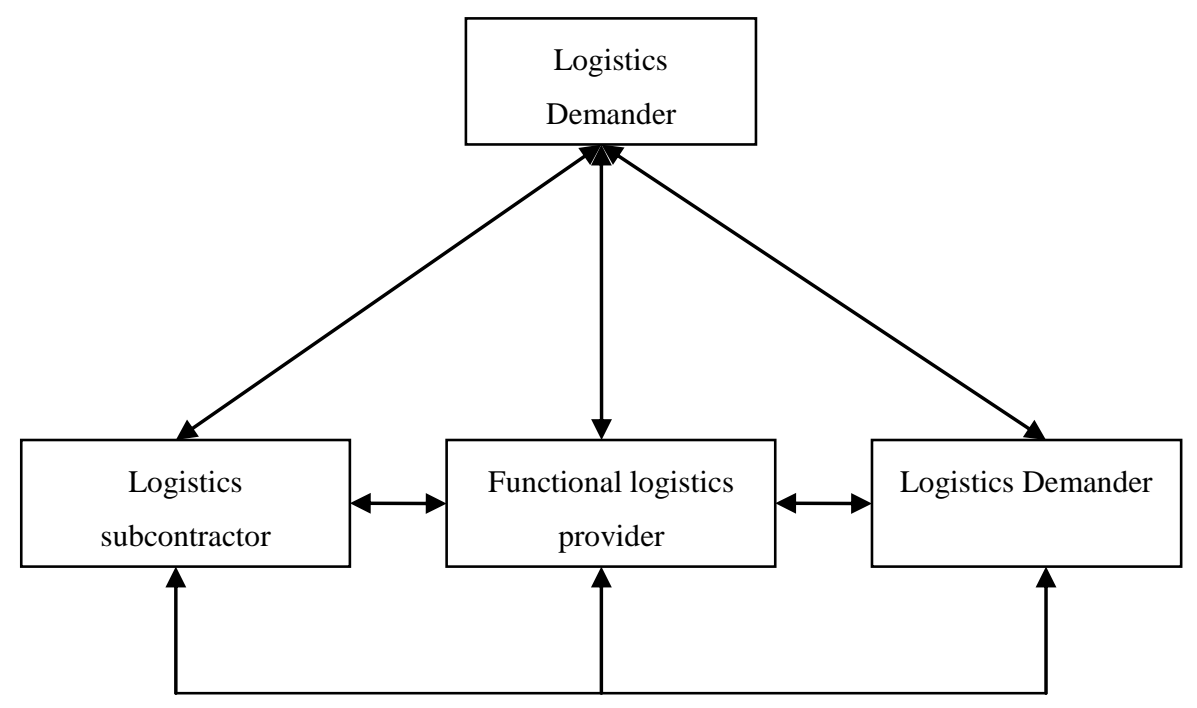

Figure 3. The Information Transmission in LSSC Embedded by IOT

(4) Achieving the credibility of information. After IOT is applied, most internal information comes from the automatic acquisition of RF network and sensor network. Information has been encrypted by encryption technology to prevent being tampered so that the reliability and authenticity of information and the reliability and independence of enterprise decision can be ensured. 
International Journal of Grid and Distributed Computing Vol.7, No.1 (2014) 


\section{The Effect of IOT on the Fund Flow i LSSC}

Fund flow is fund transmission which comes with the business of node enterprise in LSSC and an important way to realize value. The final purpose of logistics is realizing value increase. It's value increment that makes surplus value and promote virtuous circle of enterprise. Applying IOT in LSSC accelerated the turnover of the fund, improved the transparency of fund flow and reduced financial risks of node enterprises.

Accelerating the turnover of the fund. IOT makes the process of LSSC shorter and accelerated the turnover of current assets and fixed assets so that the capital turnover of node enterprises is accelerated.

Insuring the safety and the transparency of fund flow. Applying IOT helps to insure the safety of fund flow. Although the financial decision of node enterprises should be independent, IOT helps to reduce financial risks and not to breaches the agreement of LSSC and influence the operation of entire LSSC in some degree. IOT can provide effective capital flow information to node enterprises in time and real-time monitor the condition of registered bank account in every unit of LSSC through integrating internet recourses of enterprises in LSSC. Each company can monitor its own fund condition according to authorization. IOT makes the system practical and improving safety and utilization of fund.

Reducing financial risks for node enterprises. IOT accelerates logistics and fund flow of node enterprises and reduced liquidity risks. Enterprises obtain more actual information through IOT. Applying IOT intelligent algorithm can reduce investment risks in some degree, make communication between node enterprises more smooth, enhance the confidence of investor and demander, increase investment possibility from potential investor in some degree and reduce financing risk.

\section{Building the Architecture of LSSC based on IOT}

Three elements of enterprise are material flow, information flow and capital flow. There are internal material flow, information flow and capital flow because the enterprise is running. Information flow is the key for operation, material flow is insurance and capital flow is method. A complete enterprise operation pattern is built by the effective interaction of these flows. Information flow is the key of management, material/service flow is insurance and capital flow is the condition and method in LSSC. In LSSC, logistics capability of logistics integrated provider is not able to meet the demand when they get logistics project or orders. They always split and subcontract the order. The problem of purchasing logistics capability and financing should be taken into consideration. The logistics subcontractor services for them only when they have paid reasonable reward. Logistics integrated provider pass logistics capability purchasing information to sub contractors when they get capital. And the information is with the whole process of logistics capability purchasing. So the information flow and capital flow occurs. There should be a material flow/service flow to insuring the operation of logistic capability for customers, otherwise, the information flow and capital flow would be meaningless.

Applying IOT expands information sharing and integrates the information flow, material/service flow and capital flow. Information flow is the key of LSSC management. It's with the operation of material/service flow and fund flow. "Three flows" interacts with each other to be an organic unity, to improve logistics service capability and operation performance. The LSSC architecture based on IOT is shown in Figure 4. 


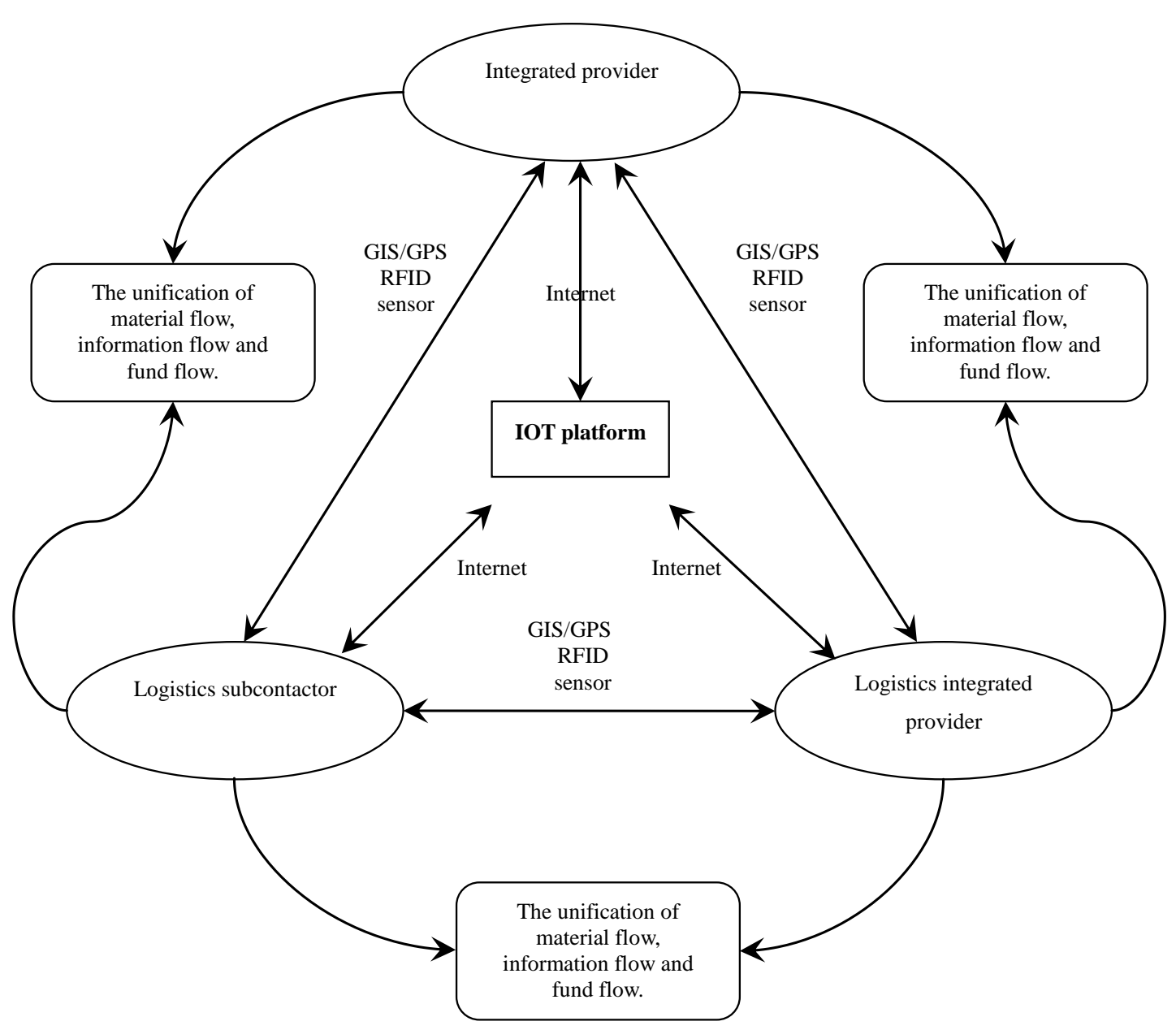

Figure 4. The LSSC Architecture based on IOT

According to Figure 4, applying IOT makes the logistics service demander, logistics service integrated provider and logistics service subcontractor exchange information through IOT platform, the transmission between LSSC and customers smooth and help enterprises to make decisions independently. It helps to smooth fund flow between LSSC and customers and to insure the fund security. It helps to improve the security and service quality of LSSC progress that the whole LSSC progress can be monitored and visible after IOT is applied. Applying IOT integrates the material flow, fund flow and information flow between customers and LSSC and makes profit for enterprises participated.

\section{Prospect}

This paper took LSSC as the object of the research and analyzed the effect of IOT on logistics/service flow, information flow and capital flow in LSSC and the effect on the structure of LSSC. On this basis, it built the architecture of LSSC based on IOT. The study on relationship between IOT and LSSC will be concentrated on the following aspects. 
(1) Research on LSSC coordination mechanism oriented to IOT. The coordination mechanism of LSSC under information and moral should be researched on. LSSC structure, that is, the situation of several subcontractors to single integrated provider, the situation of single subcontractor to several integrated providers and the situation of three-level LSSC, should be studied.

(2) Research on the optimization and application of LSSC contract based on IOT. Application of IOT can not only share information among enterprises but also realize the process of electronic information service. Research on the optimization and application of LSSC contract has theoretical and practical value.

(3) Research on the key technology of LSSC operation with IOT. LSSC is a loose network organization of logistics enterprises. The IOT operation among members realizes the coordination of LSSC. Therefore, exploring the key technology has theoretical and practical value.

\section{Acknowledgments}

The authors are thankful to the National Natural Science Foundation and the Ministry of Education of China, Shanghai Municipal Education Commission and Science and Technology Commission, and Shanghai Maritime University for providing support for this research (Grant number: 71272219; 11YJA630067; S30601; 11510501800; 20110020, respectively). The authors would also like to express their gratitude to those who have helped them with encouragement, advice, information and material, especially Prof. Robin Qiu, Prof. Tony Hu, Junyi Liu, and Jin Shang who have contributed to the research.

\section{References}

[1] A. Cui, W. Liu and X. Zhang, "Theoretical Framework of LSSC", Journal of Shanghai Maritime University, vol. 29, no. 1, (2008), pp. 1-6.

[2] A. Cui and W. Liu, "LSSC Coordination Based on Competence Division and Cooperation", vol. 29, no. 2, (2008), pp. 43-47.

[3] Z. Gao, W. Liu and Y. Wang, "Research to Logistics Service Supply Chain Based on Logistics Capability”, Chinese Market, vol. 23, (2009), pp.17-21.

[4] X. Yan, L. Sun and K. Wang, "Research on Performance Evaluation and Characteristics in Logistics Services Supply Chain”, China Mechanical Engineering, vol. 11, (2005), pp. 969-973.

[5] Z. Gao and W. Liu, "Risk Management Model of Logistics Services Supply Chain", Business Time, vol. 9, (2010), pp. 29-30.

[6] Y. Jiang, Y. Wang and Z. Deng, "Risk Analysis of Logistics Services Supply Chain in Uncertain Environments", Business Research, vol. 7, (2011), pp. 179-184.

[7] W. Liu, J. Ji and T. Zhang, "Profit Distribution Model of Two Echelon Logistics Service Supply Chain Based on Logistics Service Combination", Journal of Wuhan University Of Technology (Transportation Science \& Engineering), vol. 32, no. 4, (2008), pp. 589-592.

[8] W. Liu, J. Ji and L. Zhou, "An Order Allocation Model in Two-Echelon Logistics Service Supply Chain”, Journal Of Shanghai Jiaotong University, vol. 42, no. 9, (2008), pp. 1524-1528.

[9] W. Liu, S. Qu and S. Zhong, "Order allocation in thre-echelon logistics service supply chain under stochastic environments", Computer Integrated Manufacturing System, vol. 18, no. 1, (2012), pp. 381-388.

[10] Z. Gao, W. Liu and Z. Fan, "Transaction Cost Considered Multi-objective Optimization Model for LSSC Order Allocation”, Systems Engineering, vol. 7, (2012), pp. 32-37.

[11] A. Cui and W. Liu, "Study on Capability Coordination in Logistics Service Supply Chain with Options Contract", Chinese Journal of Management Science, vol. 2, (2009).

[12] H. Demirka and H. K. Cheng, "The risk and information sharing of application services supply chain", European Journal of Operational Research, vol. 187, no. 3, (2008), pp. 765-784.

[13] W. Liu, J. Ji, and Q. Gu, "Cooperation Quality Control and Coordination in Two-echelon Supply Chain of Logistics Service", Industrial Engineering And Management, no. 3, (2007), pp. 47-52.

[14] W. Liu, "Capability Coordination of Logistics Services Supply Chain", PhD Thesis of Shanghai Jiaotong University, Shanghai, China, (2007).

[15] Y. Li, Q. Dong and H. Sun, "Study on the Framework of Control Systems of Logistics Services Supply Chain Management”, East China Economy Management, vol. 26, no. 9, (2009), pp. 55-58. 
[16] L. Atzori, A. Iera and G. Morabito, "The internet of Things: A survey. Computer Networks", vol. 54, (2010), pp. 2787-2805.

[17] D. Giusto, A. lera, G. Morabito and L. Atzori (Eds), "The Internet of Things", Springer, (2010).

[18] X. L. Xu, T. Chen and M. Minami, "Intelligent fault prediction system based on internet of things", Computers and Mathematics with Application, vol. 64, (2012), pp. 833-839.

[19] Z. J. Zhao, Q. Shen and H. Tang, "Theory and key technologies of architecture and intelligent information processing for Internet of things", Computer Science, vol. 38, no. 8, (2011), pp. 1-8.

[20] R. Wang, "Main Character and Basic Theory for Internet of Things", Computer Science, vol. 39, no. 6A, (2012), pp. 201-203.

[21] D. Mirandi, S. Sicari, F. D. Pellegrini and I. Chlamtac, "Internet of things: Vision, applications and research challenges", Ad Hoc Networks, vol. 10, (2012), pp. 1497-1516.

[22] L. Lu and F. Liu, "Research to agricultural supply chain management based on Internet of things", Modernizing Agriculture, vol. 7, (2012), pp. 57-60

[23] H. Wang, "Research on application of Internet of things in supply chain", MsD Thesis of Shandong Jianzhu University, Jinan, China, (2009). 